\title{
Sensitization against skin resident fungi is associated with atopy in cholinergic urticaria patients
}

\author{
Sabine Altrichter ${ }^{1} \mathbb{B}$, Pia Schumacher ${ }^{1}$, Ola Alraboni ${ }^{1}$, Yiyu Wang ${ }^{1}$, Makiko Hiragun², Michihiro Hide $^{2}$ \\ and Marcus Maurer ${ }^{1 *}$ (B)
}

\begin{abstract}
Background: Cholinergic urticaria (CholU) is a common type of chronic inducible urticaria, characterized by small itchy wheals that appear upon physical exercise or passive warming. Malassezia globosa, a skin resident fungus, has been identified as an antigen that induces mast cell/basophil degranulation and wheal formation through specific IgE, in Japanese patients with atopic dermatitis and CholU. In this study we aimed in assessing the rate of IgE sensitizations against skin resident fungi in European CholU patients.
\end{abstract}

Methods: We assessed serum IgE levels to Malassezia furfur, Candida albicans and Trichophyton mentagrophytes using routine lab testing and Malassezia globosa using a newly established ELISA. We correlated the results to wheal formation and other clinical features.

Results: Four patients (of 30 tested) had elevated levels of IgE against Malassezia furfur and Candida albicans and two had elevated levels of IgE against Trichophyton mentagrophytes. Four sera (of 25 tested) had elevated levels of IgE to the Malassezia globosa antigen supMGL_1304. Sensitization to one skin fungus was highly correlated with sensitization to the other tested fungi. We saw highly significant correlations of sensitization to supMGL_1304 with wheal size in the autologous sweat skin test $\left(r_{s}=0.7, P=0.002, n=19\right)$, the Erlangen atopy score $\left(r_{s}=0.5, P=0.03, n=19\right)$, total IgE serum levels $\left(r_{s}=0.5, P=0.04, n=19\right)$ and a positive screen for lgE against common airborne/inhalant allergens $s$ $\left(s \times 1 ; r_{s}=0.54, P=0.02, n=19\right)$.

Conclusions: Sensitization to skin resident fungi including Malassezia globosa is uncommon in European CholU patients, but is associated with atopy and pronounced wheal formation upon dermal contact with their own sweat. Trial registration German Clinical Trials Registry DRKS-ID: DRKS00004277

Keywords: Cholinergic urticaria, IgE, Sensitization, Skin fungi

\section{Background}

Cholinergic urticaria (CholU) is one of the most common forms of inducible urticaria and is characterized by small itchy wheals that are induced by physical activity or

\footnotetext{
*Correspondence: marcus.maurer@charite.de

${ }^{1}$ Department of Dermatology and Allergy, Allergie-Centrum-Charité/ ECARF, Charité-Universitätsmedizin Berlin, Charitéplatz 1, 10117 Berlin, Germany

Full list of author information is available at the end of the article
}

passive warming [1-3]. There is a high reported prevalence (up to $4 \%$ ) in the general population $[4,5]$, with one publication mentioning a $20 \%$ prevalence in young adults [6], although the disease can also start later in life [7]. The severity/clinical spectrum of the disease might be broad, with some patients suffering from severe disease with frequent wheal formation and intolerable itch, which majorly reduces their quality of life $[8,9]$.

c) The Author(s) 2020. This article is licensed under a Creative Commons Attribution 4.0 International License, which permits use, sharing, adaptation, distribution and reproduction in any medium or format, as long as you give appropriate credit to the original author(s) and the source, provide a link to the Creative Commons licence, and indicate if changes were made. The images or other third party material in this article are included in the article's Creative Commons licence, unless indicated otherwise in a credit line to the material. If material is not included in the article's Creative Commons licence and your intended use is not permitted by statutory regulation or exceeds the permitted use, you will need to obtain permission directly from the copyright holder. To view a copy of this licence, visit http://creativeco mmons.org/licenses/by/4.0/. The Creative Commons Public Domain Dedication waiver (http://creativecommons.org/publicdomain/ zero/1.0/) applies to the data made available in this article, unless otherwise stated in a credit line to the data. 
The underlying pathogenesis of CholU is not understood, but several mechanisms have been proposed $[10,11]$. Many studies have provided evidence that IgEmediated mast cell activation is of major importance in the pathogenesis of CholU. Patients exhibit high rates of atopy [12], which has been linked to higher levels of disease activity and to elevated total IgE serum levels. CholU is adoptively transferable to healthy subjects by injecting CholU patient serum into healthy skin, suggesting a transferable serum factor and antigen-antibody driven disease mechanism [13]. It is also well established that some CholU patients develop wheal and flare type reactions upon skin testing with their own sweat [13], pointing towards a type-I allergy against sweat. Further evidence that IgE-mediated effects play a major role in CholU comes from reports of successful treatment of patients with anti-IgE (omalizumab) [14, 15]. Nevertheless, the antigen causing the IgE-mediated symptoms in CholU was not known for a long time. More recently, Hiragun et al. detected elevated levels of IgE against the lipophilic yeast-like fungi Malassezia globosa in patients with atopic dermatitis and CholU and identified a frequently reactive antigen (supMGL_1304) in human sweat [16-18]. Sweat-derived antigens have also been shown to be of functional relevance, as these antigens were able to induce degranulation of mast cells and basophils in sensitized atopic dermatitis patients $[19,20]$, a disease where skin resident fungi are thought to play an important role in the pathogenesis of the disease [21].

These studies were performed in Japan. To date it is not known whether patients from other parts of the world also show these sensitizations, whether they account for the skin reaction with autologous sweat and whether they are of clinical relevance. To address this, we analyzed specific IgE serum levels to known skin resident fungi, including the Malassezia globosa antigen supMGL_1304, and correlated the results with wheal formation in the autologous sweat skin test (ASwST) and other clinical features.

\section{Materials and methods Study subjects}

In this study, 39 patients with CholU were recruited at the UCARE Center [22] of the Department of Dermatology and Allergy, Charité-Universitätsmedizin, Berlin for provocation testing, sweat collection, skin testing and extensive clinical characterization. Patients were advised to stop taking antihistamines at least 3 days prior to any tests. None of the patients had taken local or systemic glucocorticoids or other immunosuppressive therapy 2 weeks before the tests. As a control group, 70 healthy individuals were recruited and underwent the same procedures, except provocation testing. The study was approved by the Ethics Committee of the CharitéUniversitätsmedizin Berlin (EA4/124/10), and is registered in the German Clinical Trials Registry (DRKS-ID: DRKS00004277). Other aspects of the study will be published elsewhere.

Demographic and clinical characteristics of the patients and healthy controls are shown in Table 1.

\section{Clinical assessments}

Patients and healthy controls were assessed for their clinical history and comorbidities. Atopic skin diathesis (atopic predisposition) was also assessed using the Erlanger Atopy score questionnaire [23]. For CholU patients, disease duration was recorded and disease severity was rated using the Cholinergic Urticaria Severity Index (CholUSI). This is a sum score that takes into account the frequency of CholU symptoms (<once a month $=0$ point; once a month $=1$ point; $>$ once a month $=2$ points; once a week $=3$ points; $>$ once a week $=4$ points; daily $=5$ points; $>$ daily $=6$ points), eliciting factors (one point each for: physical exercise, hot bath, hot shower, emotional stress, hot food, sauna, other), duration of skin lesions $(<5 \mathrm{~min}=0$ point; 5 $10 \mathrm{~min}=1$ point; $10-20 \mathrm{~min}=2$ points; $20-30 \mathrm{~min}=3$ points; $30-60 \mathrm{~min}=4$ points; $>1 \mathrm{~h}=5$ points) and itch (none $=0$ point; mild $=1$ point; moderate $=2$ points; severe $=3$ points). The CholUSI score ranges from 0 to 21 points: $<5$ points $=$ very mild CholU; $5-9$ points $=$ mild CholU; $\quad 10-15$ points $=$ moderate $\quad$ CholU; $>15$ points $=$ severe CholU [24].

\section{Sauna provocation test}

After showering without soap and completely drying, patients were put in a large plastic bag (polyethylene, food safe grade, Ratioform $\mathrm{GmbH}$, Pliening, Germany)

Table 1 Clinical characteristics of study participants

\begin{tabular}{|c|c|c|c|}
\hline & $\begin{array}{l}\text { CholU patients } \\
n=39\end{array}$ & $\begin{array}{l}\text { Healthy controls } \\
n=70\end{array}$ & $P$ value \\
\hline \multicolumn{4}{|l|}{ Age [years] } \\
\hline Median (IQR) & $31.5(23.3-46.5)$ & $31.0(27.0-34.0)$ & n.s. \\
\hline \multicolumn{4}{|l|}{ Sex } \\
\hline$M: F$ & $16: 23$ & $40: 30$ & n.s. \\
\hline \multicolumn{4}{|l|}{$\mathrm{BMI}\left[\mathrm{kg} / \mathrm{m}^{2}\right]$} \\
\hline Median (IQR) & $24.2(20.8-26.7)$ & $22.9(20.2-24.7)$ & n.s. \\
\hline \multicolumn{4}{|c|}{$\begin{array}{l}\text { Persistance of disease } \\
\text { [years] }\end{array}$} \\
\hline Median (range) & $6.0(3.0-12.8)$ & - & - \\
\hline \multicolumn{4}{|l|}{ Total lgE [kU/l] } \\
\hline $\begin{array}{l}\text { Median (range), } \\
n=29\end{array}$ & $164.0(46.8-291.0)$ & - & - \\
\hline
\end{tabular}

IQR interquartile range, $M$ male, $F$ female 
that covered the entire body, apart from the head. They then took a 15 min sauna at $80{ }^{\circ} \mathrm{C}$, during which sweat was collected in the bag. The total sweat volume was measured and the sweat was immediately frozen at $-20^{\circ} \mathrm{C}$ and at $-80^{\circ} \mathrm{C}$ for long term storage.

\section{Pulse controlled ergometry test}

Eighteen patients underwent pulse controlled ergometry testing as described elsewhere [25]. They were assessed for the time to onset of sweating using the iodine-starch reaction (sweat test according to Minor), the time to onset of whealing and the increase in heart rate at the onset of whealing. Patients were assessed for their symptoms at the end of the test (itching: no itch $=0$, mild itch $=1$, moderate itch $=2$, severe itch $=3$; whealing: no whealing $=0,1-20$ wheals $=1,21-50$ wheals $=2,>50$ wheals $=3$ ) to result in a urticaria activity score at the time of provocation (UASprovo) with a sum score between 0 and 6 points.

\section{Skin tests}

Skin tests were performed at least $24 \mathrm{~h}$ after provocation testing. For the ASwST, the patient's sweat was defrosted on the day of testing, sterile filtered using Sartorius ${ }^{\mathrm{TM}}$ Minisart NML (sterile, Sartorius AG, Göttingen, Germany) and diluted using sterile $\mathrm{NaCl} 0.9 \%$ under sterile conditions. The sweat was diluted (1:100) and intracutaneously injected (i.c., $50 \mu \mathrm{l}$ ) using a $1 \mathrm{ml}$ syringe (Plastipak $^{\mathrm{TM}}, 1 \mathrm{ml}$, Becton-Dickinson (BD), Heidelberg, Germany) and a needle for subcutaneous injection (27 G $1 / 2,13 \mathrm{~mm}, \mathrm{BD})$, as described by Kozani et al. [21].

For the autologous serum skin test (ASST) [26], $50 \mu \mathrm{l}$ freshly drawn patient serum was injected intradermally. For the acetylcholine i.c. (ACh i.c.) test, acetylcholine was diluted with $\mathrm{NaCl} 0.9 \%$ solution under sterile conditions to a final concentration of $100 \mu \mathrm{g} / \mathrm{ml}(0.01 \%)$ as described by Fukunaga et al. [27] and injected intradermally. Detailed results of the ACh i.c. test will be reported elsewhere.

$\mathrm{NaCl}$ 0.9\% solution and histamine $100 \mu \mathrm{g} / \mathrm{ml}(0.01 \%$; Bencard Allergie $\mathrm{GmbH}$, Munich, Germany) were used for i.c. testing as negative and positive controls, respectively. The diameter of the resulting wheal and flare reactions were measured using a transparent ruler with $1 \mathrm{~mm}$ grading after $15 \mathrm{~min}$ and $30 \mathrm{~min}$. The skin tests were considered positive if the wheal induced by sweat or ACh was $\geq 1.5 \mathrm{~mm}$ bigger than that induced by the negative control $(\mathrm{NaCl} 0.9 \%)$.

\section{IgE measurements}

IgE levels were measured using the Immuno CAP System $^{\circledR}$ (Phadia Laboratory Systems, Thermo Fisher Scientific Inc, Uppsala, Sweden) at a central laboratory
(Labor Berlin GmbH, Berlin, Germany). Serum was analysed for total IgE, IgE against common airborne/ inhalant allergens (D1 house dust mite, E1 cat, E5 dog, G6 timothy, G12 rye, M2 Cladosporium herbarum, T3 birch, W6 mugwort), and specific IgE to Candida albicans, Malassezia furfur and Trichophyton mentagrophytes.

Total IgE levels $>100 \mathrm{kU} / \mathrm{l}$ were considered elevated. Specific IgE levels of $>0.1 \mathrm{kU} / \mathrm{l}$ were considered as detectable, and levels of $\geq 0.35 \mathrm{kU} / \mathrm{l}$ as sensitization (0.00-0.34 CAP-Class 0, 0.35-0.70 CAP-Class 1, 0.703.50 CAP-Class 2, 3.50 to $<17.5$ CAP Class $3,17.5$ to $<50.0$ CAP Class 4, 50.0-100.0 CAP-Class 5, > 100.0 CAP-Class 6).

\section{SupMGL_1304 IgE ELISA}

IgE against supMGL_1304 from Malassezia globosa were detected using an ELISA as described by Kan et al. and Hiragun et al. [17, 28]. In brief, 96-well plates (highbinding, Greiner bio-one, Frickenhausen, Germany) were coated with $10 \mu \mathrm{g} / \mathrm{ml}$ mouse monoclonal antibody against purified supMGL_1304 (Smith-2 antibody; generation of antibody has been described in [18] overnight at $4{ }^{\circ} \mathrm{C}$. Plates were blocked with $2 \%$ bovine serum albumin in phosphate buffered saline (BSA-PBS) for $1 \mathrm{~h}$ at room temperature and washed with $0.05 \%$ tween $20-\mathrm{PBS}$. The coated plates were then incubated with $1 \mu \mathrm{g} / \mathrm{ml}$ purified supMGL_1304 in $0.1 \%$ BSA-PBS for 90 min at room temperature. Patients' serum was diluted 1:40 with 1\% BSAPBS and incubated after washing of the plates at room temperature for $90 \mathrm{~min}$. After washing, the plates were incubated with peroxidase-labeled antibody to human IgE ( $\varepsilon$-chain specific, KPL, Gaithersburg, MD, USA) diluted 1:3000 with 1\% BSA-PBS at room temperature for $1 \mathrm{~h}$. After washing, TMB Microwell Peroxidase Substrate was added and incubated for $30 \mathrm{~min}$. The reactions were stopped with TMB Stop Solution (KPL). The optical density was read at $450 \mathrm{~nm}$ using an automatic plate reader (Benchmark Plus, Bio-Rad, Hercules, CA, USA). Pooled serum of Japanese patients with atopic dermatitis was used as standard in various dilutions (1:10 to 1.1208 in $1 \%$ BSA-PBS). Results are given as arbitrary units (AU) in correlation with the standard serum.

\section{Statistical analyses}

Statistical analyses were performed using IBM SPSS Statistics version 23 and GraphPad Prism Version 6.0. Binominal variables were analyzed using Chi-square test or Fisher Exact test for small categorical numbers $(<5)$. Non-parametric continuous variables were compared using Mann-Whitney-U test. Correlations were analyzed 
using Spearman rank test. $P<0.05$ was considered to indicate statistical significance.

\section{Results}

Sensitization against skin resident fungi can be detected in a small population of European CholU patients

Results from the specific IgE testing against the fungi Candida albicans a, Malassezia furfur and Trichophyton mentagrophytes were available for 30 patients (Fig. 1a). Considering $0.1 \mathrm{kU} / \mathrm{l}$ as the limit for specific IgE levels, four patients (13\%) had clearly elevated levels against Malassezia furfur. Two patients had IgE levels in the CAP-Class 2, and two had IgE levels in the CAP-Class 3 , reaching levels up to $14.2 \mathrm{kU} / \mathrm{l}$. More patients $(\mathrm{n}=8$; 26\%) had detectable IgE levels against Candida albicans, but half of them were in the CAP-Class 0. Three had levels in CAP-Class 2 and one in CAP-Class 3. IgE against Trichophyton mentagrophytes. was detected in only three patients (10\%), with one patient in CAP-Class 0 and two in CAP-Class 2.

Specific IgE against Malassezia furfur positivity was highly correlated with detectable levels of IgE against the other fungi (Candida albicans.: $\mathrm{r}_{\mathrm{s}}=0.59, P=0.001$; Trichophyton mentagrophytes: $\mathrm{r}_{\mathrm{s}}=0.68, P<0.001$ ).

IgE against the Malassezia globosa antigen supMGL_1304 was elevated in a small number of CholU patients and was well correlated with levels of specific $\lg \mathrm{E}$ against the other skin fungi

Using IgE levels from 20 healthy controls, who reported no known sensitization and had a normal low total IgE level below $100 \mathrm{kU} / \mathrm{l}$, a cut-off was set at the $95 \%$ percentile (19.4 AU).

Of the 25 CholU patients who underwent testing, four (12\%) had levels of IgE against supMGL_1304 above the set $95 \%$ percentile, with values ranging from 21.8 to 1594.5 AU (Fig. 1b). These values showed a high correlation with sensitization against the measured skin resident fungi (Malassezia furfur $\mathrm{r}_{\mathrm{s}}=0.633, P=0.013$; Candida albicans: $\mathrm{r}_{\mathrm{s}}=0.548, P=0.037$; Trichophyton mentagrophytes: $\left.\mathrm{r}_{\mathrm{s}}=0.555, P=0.042\right)$. Three of the four positive sera also showed elevated IgE levels to all the other three skin resident fungi.

Sensitization to supMGL_1304 was correlated with skin reactions against autologous sweat in CholU patients, but not with ASST or ACh i.c. positivity

The ASwST (using 1:100 diluted sweat) was performed in 38 CholU patients. Twenty-eight patients (73.7\%) developed a wheal 15 min after injection, compared with only one $(1.4 \%)$ of the 69 healthy controls $(P<0.001)$. All four CholU patients with sensitization to supMGL_1304 had a positive reaction in the ASwST. Of the 34 patients
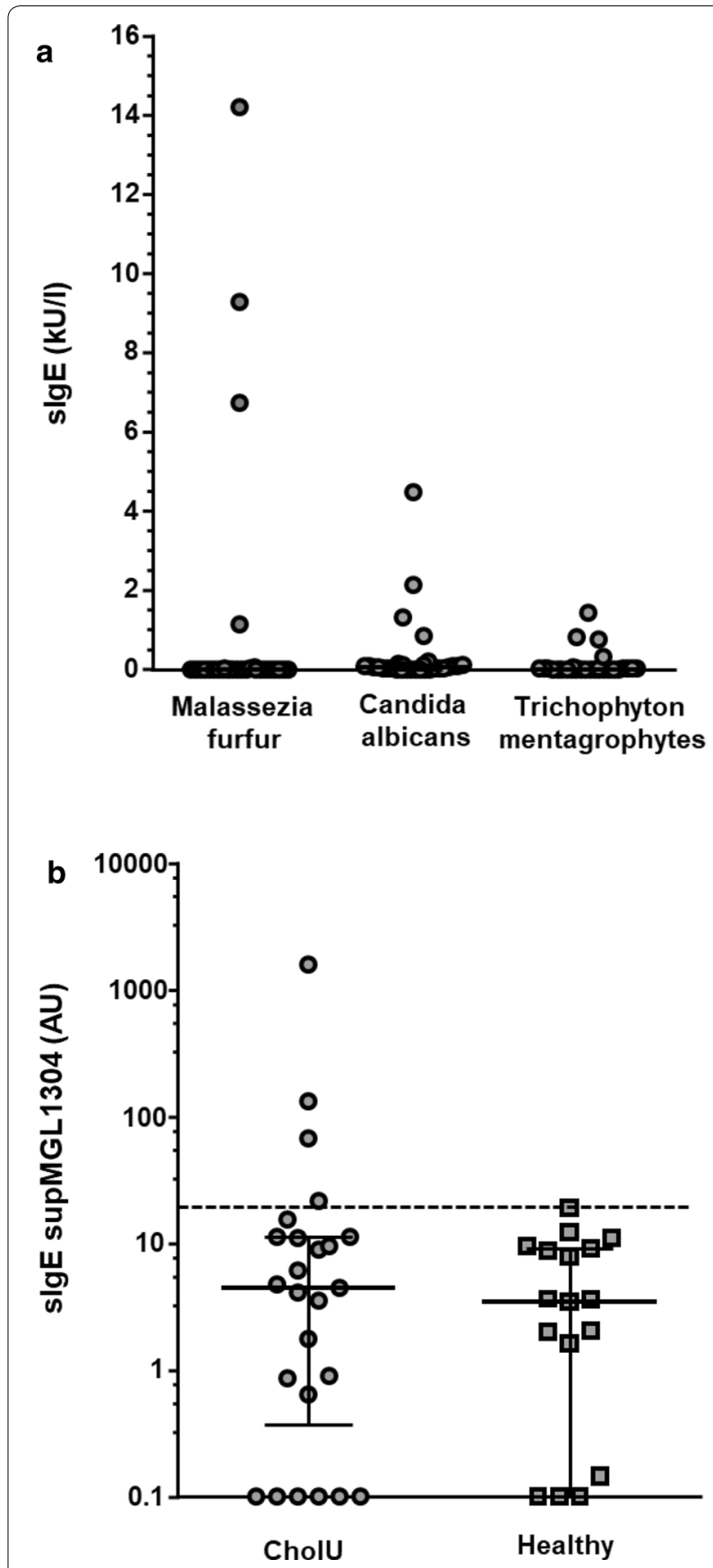

Fig. 1 Specific lgE levels against skin fungi in CholU patients $(n=30)$ (a), and against supMGL-1304 in CholU patients $(n=25)$ and healthy controls $(n=20)(\mathbf{b})$. Individual patients are displayed as dots. $\mathbf{b}$ Shows median and interquartile ranges of specific lgE levels against supMGL-1304. 95\% percentile calculated from healthy controls is represented by a dashed line

without sensitization to supMGL_1304, 24 (73.5\%) had a positive reaction. In CholU patients, we saw a highly significant correlation of sensitization to supMGL_1304 with wheal size in the ASwST $\left(r_{s}=0.7, P=0.002, n=19\right)$. 
Patients with IgE against supMGL_1304 had significantly larger wheals in the ASwST compared with the rest of the patients (mean $10.5 \pm 2.7 \mathrm{~mm}$ vs. $5.0 \pm 4.0 \mathrm{~mm}, P=0.026$; Fig. 2). No correlation or differences were seen with the wheal size of the histamine positive control (data not shown).

Serum autoreactivity and Ach i.c. reactivity were also assessed in both CholU patients and healthy controls. Twelve (31.6\%) of the CholU patients but only 7 (10.1\%) of the healthy controls showed a positive reaction in the ASST $(P=0.008)$. In contrast to the ASwST, no significant correlation with the sensitization to supMGL_1304 was seen $\left(\mathrm{r}_{\mathrm{s}}=-0.44, P=0.06, \mathrm{n}=19\right)$. None of the patients with elevated IgE levels to supMGL_1304 had a positive reaction in the ASST and only one of these patients developed a wheal in the ACh i.c test. However, all patients with elevated IgE levels to supMGL_1304 developed a flare reaction in the ACh i.c. test, compared to the remaining patients where only about $50 \%$ exhibited such a skin reaction (Table 2).

\section{Sensitization to supMGL_1304 was associated with atopic predisposition (Erlangen Atopy score, total lgE)}

In CholU patients, levels of IgE against supMGL_1304 showed a positive correlation with the Erlangen atopy score $\left(\mathrm{r}_{\mathrm{s}}=0.53, P=0.02, \mathrm{n}=19\right)$ and with total IgE serum levels $\left(\mathrm{r}_{\mathrm{s}}=0.54, P=0.04, \mathrm{n}=19\right)$, but not with sensitization to inhalant allergens $\left(\mathrm{SX} 1 \mathrm{r}_{\mathrm{s}}=0.31, P=0.30, \mathrm{n}=13\right)$.

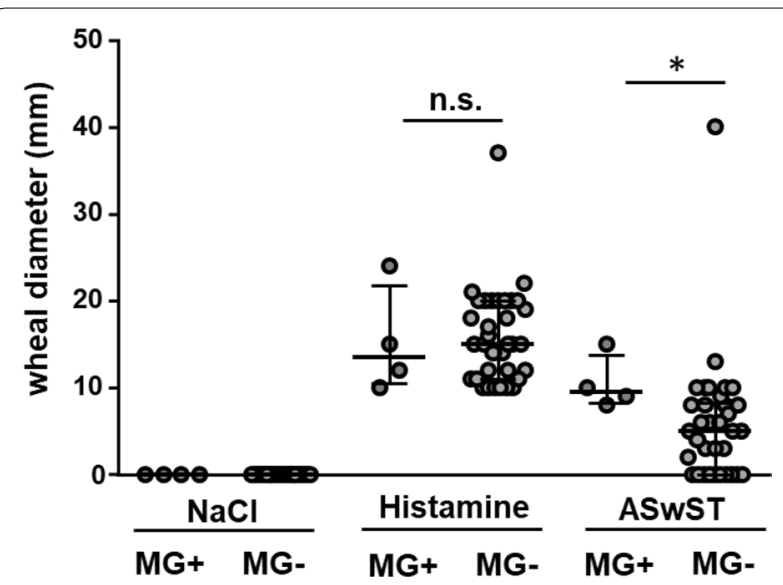

Fig. 2 Skin reactivity in the ASwST with histamine as positive and $\mathrm{NaCl}$ as negative controls. Differences between the CholU patients with elevated specific IgE levels against supMGL-1304 (MG+; $n=4)$ and CholU patients with normal low supMGL-1304 (MG-, $n=21)$ are shown. Median and interquartile ranges of the largest wheal size measured are depicted
Sensitization to supMGL_1304 was associated with female sex and higher UASprovo scores, driven by intensity of itch All four patients with clearly elevated serum levels of IgE anti supMGL_1304 were females. Due to the low numbers, interpretation of the statistical significance of these results must be made with caution.

Clinically, levels of IgE against supMGL_1304 were significantly correlated to the skin reactivity in the pulse controlled ergonometry test. There was a good and significant correlation with the UASprovo sum score $\left(r_{s}=0.84, P=0.004, n=10\right)$. Analysis of the wheal and itch scores revealed that this correlation was driven by itch $\left(\mathrm{r}_{\mathrm{s}}=0.84, P=0.006, \mathrm{n}=10\right)$, but not wheal $\left(\mathrm{r}_{\mathrm{s}}=0.41\right.$, $P=0.40, \mathrm{n}=10)$, indicating that sensitization to supMGL_1304 was associated with more severe itch in the CholU patients.

No correlation was seen with age, disease persistance, frequency of symptoms or factors that trigger sweating (data not shown). Specific IgE levels against supMGL_1304 in CholU patients were negatively correlated with body weight $\left(\mathrm{r}_{\mathrm{s}}=-0.55, P=0.02, \mathrm{n}=19\right)$, indicating that sensitization to supMGL_1304 is not associated with large skin surface area/obesity.

\section{Discussion}

To our knowledge, this is the first screening of CholU patients for specific IgE against skin fungi in European CholU patients. Sensitization to Malassezia globosa is well documented in Japanese patients [17].

We found that a small subgroup of patients (up to 26\%) have IgE against Candida albicans, Malassezia furfur and Trichophyton mentagrophytes. Interestingly, there was a high correlation between sensitization to the different fungi, indicating that there is a subgroup of CholU patients who are prone to sensitization against skin resident fungi. In patients with atopic dermatitis, skin resident fungi are thought to play an important role in the pathogensis of the disease via altered cytokine responses to the fungus $[29,30]$. Whether similar responses are induced in CholU has not yet been investigated.

The proportion of patients with elevated serum levels of IgE against Malassezia globosa was considerably lower in our study than in a previous study of Japanese patients [17] (12\% vs. $58 \%)$. This may be due to the difference in climate between Germany and Japan, which could lead to lower levels of Malassezia globosa colonization in German patients [31,32]. Alternatively, there may be genetic differences between the German Caucasian and Japanese populations that affect sensitivity to skin resident fungi.

In our study, patients with sensitization to supMGL_1304 had more pronounced skin reactions in the ASwST and a correlation of the wheal size in the ASwST with levels of IgE against supMGL_1304. Several 
Table 2 Clinical characteristics of CholU patients with elevated specific IgE levels against supMGL-1304 (MG+) and CholU patients with normal low supMGL-1304 (MG-)

\begin{tabular}{|c|c|c|c|}
\hline & $\begin{array}{l}\text { MG+ } \\
n=4\end{array}$ & $\begin{array}{l}\text { MG- } \\
n=21\end{array}$ & $P$ value \\
\hline \multicolumn{4}{|l|}{ Age [years] } \\
\hline Median (range) & $35.5(21-57)$ & $31.0(18-55)$ & \\
\hline Mean $\pm S D$ & $37.3 \pm 9.0$ & $32.9 \pm 2.5$ & 0.504 \\
\hline \multicolumn{4}{|l|}{ Sex } \\
\hline$M: F$ & $0: 4$ & 11:10 & 0.105 \\
\hline \multicolumn{4}{|l|}{ BMI $\left[\mathrm{kg} / \mathrm{m}^{2}\right]$} \\
\hline Median (range) & $21.4(20.2-25.2)$ & $24.7(20.0-32.3)$ & \\
\hline Mean \pm SD & $22.1 \pm 1.1$ & $25.1 \pm 0.8$ & 0.119 \\
\hline \multicolumn{4}{|l|}{ Clinical data } \\
\hline \multicolumn{4}{|l|}{ Persistence of disease [years] } \\
\hline Median (range) & $3.5(1.0-29.0)$ & $5.0(1.0-20.0)$ & \\
\hline Mean \pm SD & $9.3 \pm 6.6$ & $7.6 \pm 1.3$ & 0.681 \\
\hline CholUSI & & $n=19$ & \\
\hline Median (range) & $16.5(15-19)$ & $16.0(10-20)$ & \\
\hline Mean $\pm S D$ & $16.7 \pm 0.8$ & $16.0 \pm 0.5$ & 0.540 \\
\hline UAS Provo & $\mathrm{n}=3$ & $n=10$ & \\
\hline Median (range) & $5(5,6)$ & $4(3-5)$ & \\
\hline Mean \pm SD & $5.3 \pm 0.5$ & $4.1 \pm 0.7$ & 0.036 \\
\hline Itch Score Provo & $n=3$ & $n=10$ & \\
\hline Median (range) & $2(2,3)$ & $1(1,2)$ & \\
\hline Mean $\pm S D$ & $2.3 \pm 0.5$ & $1.3 \pm 0.5$ & 0.069 \\
\hline Wheal Score Provo & $n=3$ & $n=10$ & \\
\hline Median (range) & $3(3)$ & $3(2,3)$ & \\
\hline Mean \pm SD & $3 \pm 0$ & $2.8 \pm 0.4$ & 0.167 \\
\hline \multicolumn{4}{|l|}{ Atopic features } \\
\hline Erlangen Atopy score & & $\mathrm{n}=\mathbf{2 0}$ & \\
\hline Median (range), & $14.5(12-20)$ & $9.0(5-14)$ & \\
\hline Mean \pm SD & $15.3 \pm 1.7$ & $9.0 \pm 0.7$ & 0.026 \\
\hline Total lgE [kU/l] & & $n=15$ & \\
\hline Median (range) & $1360.5(278.0-4377.0)$ & $71.9(14.8-600.0)$ & \\
\hline Mean \pm SD & $1844.0 \pm 886.0$ & $154.5 \pm 169.2$ & 0.152 \\
\hline \multirow[t]{2}{*}{ Pos. Sx1 screening (inhalative allergen mix) } & $n=3$ & $n=15$ & \\
\hline & $2(67 \%)$ & $9(60 \%)$ & 1.0 \\
\hline \multirow[t]{2}{*}{ Pos. slgE to other skin resident fungi } & & $\mathrm{n}=17$ & \\
\hline & $3(75 \%)$ & $1(6.3 \%)$ & 0.012 \\
\hline \multicolumn{4}{|l|}{ Skin testings } \\
\hline ASwST 1:100 pos. (n) & $4(100 \%)$ & $15(71 \%)$ & 0.540 \\
\hline ASwST wheal size diameter (mm) & & $n=20$ & \\
\hline Median (range) & $9.5(0.8-1.5)$ & $5.5(0-1.3)$ & \\
\hline Mean \pm SD & $10.5 \pm 2.7$ & $5.6 \pm 4.2$ & 0.04 \\
\hline ASwST flare size diameter (mm) & & $n=20$ & \\
\hline Median (range) & $33.5(1.4-3.7)$ & $12.0(0-4.5)$ & \\
\hline Mean $\pm S D$ & $29.5 \pm 0.9$ & $17 \pm 4$ & 0.060 \\
\hline ASST pos (n) & $0(0 \%)$ & $5(24 \%)$ & 0.55 \\
\hline ASST wheal size diameter (mm) & & $n=20$ & \\
\hline Median (range) & $0(0)$ & $0(0-9)$ & \\
\hline Mean \pm SD & $0 \pm 0$ & $1.9 \pm 3.2$ & 0.017 \\
\hline
\end{tabular}


Table 2 (continued)

\begin{tabular}{|c|c|c|c|}
\hline & $\begin{array}{l}\text { MG+ } \\
n=4\end{array}$ & $\begin{array}{l}\text { MG- } \\
n=21\end{array}$ & $P$ value \\
\hline ASST flare size diameter (mm) & & $n=20$ & \\
\hline Median (range) & $0(0-4)$ & $0(0-19)$ & \\
\hline Mean \pm SD & $10 \pm 1.7$ & $5.2 \pm 8.9$ & 0.075 \\
\hline ACh i.c. pos (n) & $1(25 \%)$ & $10(47.6 \%)$ & 0.604 \\
\hline \multicolumn{4}{|l|}{ ACh i.c wheal size diameter (mm) } \\
\hline Median (range) & $0(0-0.8)$ & $0(0-10)$ & \\
\hline Mean \pm SD & $2.0 \pm 1.2$ & $3.1 \pm 3.9$ & 0.626 \\
\hline \multicolumn{4}{|l|}{ ACh i.c. flare size diameter (mm) } \\
\hline Median (range) & $5.0(5-55)$ & $5.0(0-35)$ & \\
\hline Mean \pm SD & $19 \pm 20.9$ & $13.3 \pm 1.6$ & 0.0675 \\
\hline
\end{tabular}

Statistical significant differences are shown in bold, trends in italics

ACh i.c. acetylcholine intracutaneous injection, ASwST autologous sweat skin test, ASST autologous serum skin test, BMI body mass index, CholUSI Cholinergic Urticaria Severity Index, Provo provocation, SD standard deviation, UAS urticaria activity score

mechanisms could explain this observation. Firstly, the pronounced skin reaction may be due to sensitization to Malassezia globosa and a true IgE-mediated Type I allergy to Malassezia globosa. This may be facilitated by sweat, components of which have been shown to increase the growth rate of Malassezia globosa [32]. Alternatively, sensitization to Malassezia could have a direct action on mast cells, increasing histamine content and interleukin-6 production [33], and thereby augmenting histamine release caused by other activation mechanisms. A combination of these two mechanisms is also possible. To answer these questions, functional test using basophils or mast cells would be needed, and should be performed in the future.

The more pronounced skin reactions in the ASwST on the other hand cannot be explained with a general hyperreactive skin in the supMGL_1304 sensibilized patients, as their reactivity to histamine per se, did not show any detectable differences. Also no correlation with the ASST has been seen.

Overall, there was a high number of patients, who showed positive reactions in the ASwSt, but had no detectable sensitizations to the analyzed fungi. This may be due to sensitization to yet unidentified sweat antigens, directly mast cell-activating factors, or histamine or similar mediators that are contained in the sweat of patients with CholU.

Sensitization to supMGL_1304 was strongly associated with atopic skin features and total IgE levels, but not with sensitization to common airborne/inhalant allergens. This is consistent with previous studies that showed a high rate of atopy in CholU patients [12, 34] and sensitization to supMGL_1304 in both CholU and atopic dermatitis patients [35]. This association fits the hypothesis that defects in the skin barrier could facilitate antigen uptake and subsequent sensitization [36]. Also, the microbes themselves could induce skin barrier defects that in turn initiate the sensitization [37], leading to a reinforcing feed-back loop.

Clinically, sensitization to supMGL_1304 was associated with higher symptom scores in the pulse-controlled ergonometry test, specifically itch. The reason for this remains unclear and warrants further investigation. To our knowledge, no other publication has reported such a correlation.

In our small cohort of four patients with elevated IgE levels to supMGL_1304, all patients were female. This was unexpected, as greater skin colonization by Malassezia globosa has been reported in males [31]. However, atopy has been associated with female sex in CholU patients [12], and we have shown a strong correlation between IgE against supMGL_1304 and atopy in our study. Overall, the number of patients sensibilised to supMGL_1304 was low and significant conclusions cannot be drawn. No correlation was seen with other assessed clinical factors such as age, disease persistance, frequency of symptoms or factors that trigger sweating.

The detection of specific IgE to Malassezia globosa raises the question of whether antimycotic treatment could be beneficial in CholU patients. In atopic dermatitis, clinical studies have not provided any clear evidence that antimycotic treatment leads to a significant improvement in symptoms [38, 39], but patients were usually not screened for sensitization to Malassezia globosa In CholU, desensitization therapy using autologous sweat or Malassezia globosa peptides has been shown to be beneficial for patients with intractable CholU due to sweat allergy [35, 40, 41]. Furthermore, intensified showering or tannin acid have been proposed as therapeutic regimens in patients with atopic dermatitis sensitized 
to Malassezia globosa [41]. Further work, including placebo-controlled studes, is needed in this area.

The main limitation of our study is the low number of CholU patients who displayed a sensitization to Malassezia globosa Furthermore, data on the actual skin residency of skin fungi, their subspecies and numbers were not captured.

\section{Conclusion}

In summary, this study showed that a subgroup of German Caucasian CholU patients displayed sensitization to skin resident fungi and that this sensitization was associated with atopic predisposition and more pronounced skin reactions to sweat provocation tests. Antifungal treatments could be a therapeutic option in these patients, if skin colonization with fungi is present and increased.

\section{Abbreviations \\ ACh: Acetylcholine; ASST: Autologous serum skin test; ASwST: Autolo- gous sweat skin test; AU: Arbitrary unit; CholU: Cholinergic urticaria; i.c.: Intracutaneous.}

\section{Acknowledgements}

We want to thank Sophie Harms for administrative assistance.

\section{Authors' contributions}

SA coordinated the study, collected patient data, was involved in statistical analysis and drafted the manuscript. YW was involved in data management. OA was involved in data management, statistical analysis and manuscript preparation. PS collected patient data and was involved in data management. $\mathrm{MH}$ conducted laboratory assessments of patient sera. $\mathrm{MH}$ provided lab material and supervised the laboratory assessment, and was involved in manuscript preparation and proof-reading. MM was the overall study coordinator and was involved in manuscript preparation and proof-reading. All authors read and approved the final manuscript.

\section{Funding}

This study was supported by intramural funding of the Charité-Universitätsmedizin Berlin, Germany.

\section{Availability of data and materials}

Raw data were generated at Charité-Universitätsmedizin Berlin, Germany. Derived data supporting the findings of this study are available from the corresponding author on request.

\section{Ethics approval and consent to participate}

The study was approved by the Ethics Committee of the Charité-Universitätsmedizin Berlin (EA4/124/10).

\section{Consent for publication}

Not applicable.

\section{Competing interests}

Sabine Altrichter is or recently was a speaker and/or advisor for and/or has received research funding from Allakos, AstraZeneca, Moxie, Sanofi and Novartis. Yiyu Wang, Ola Alraboni, Pia Schumacher, Makiko Hiragun has no competing interests. Mchihiro Hide is or recently was a speaker and/or advisor for and/or has received research funding from. Marcus Maurer is or recently was a speaker and/or advisor for and/or has received research funding from Allakos, Aralez, Genentech, GSK, Menarini, Merckle Recordati, Moxie, Novartis, Sanofi, MSD, and Uriach.

\section{Author details}

${ }^{1}$ Department of Dermatology and Allergy, Allergie-Centrum-Charité/ECARF, Charité-Universitätsmedizin Berlin, Charitéplatz 1, 10117 Berlin, Germany.

${ }^{2}$ Department of Dermatology, Integrated Health Sciences, Institute of Biomedical and Health Sciences, Hiroshima University, Hiroshima, Japan.

Received: 9 March 2020 Accepted: 16 May 2020

Published online: 01 June 2020

References

1. Magerl M, Altrichter S, Borzova E, Gimenez-Arnau A, Grattan CE, Lawlor $F$, et al. The definition, diagnostic testing, and management of chronic inducible urticarias - The EAACI/GA(2) LEN/EDF/UNEV consensus recommendations 2016 update and revision. Allergy. 2016;71(6):780-802 (Epub 2016/03/19).

2. Kim JE, Eun YS, Park YM, Park HJ, Yu DS, Kang H, et al. Clinical characteristics of cholinergic urticaria in Korea. Ann Dermatol. 2014;26(2):189-94 (Epub 2014/06/03).

3. Krupa Shankar DS, Ramnane M, Rajouria EA. Etiological approach to chronic urticaria. Indian J Dermatol. 2010;55(1):33-8 (Epub 2010/04/27).

4. Moore-Robinson M, Warin RP. Some clinical aspects of cholinergic urticaria. Br J Dermatol. 1968;80(12):794-9 (Epub 1968/12/01).

5. Godse K, Farooqui S, Nadkarni N, Patil S. Prevalence of cholinergic urticaria in Indian adults. Indian Dermatol Online J. 2013;4(1):62-3 (Epub 2013/02/26)

6. Zuberbier T, Althaus C, Chantraine-Hess S, Czarnetzki BM. Prevalence of cholinergic urticaria in young adults. J Am Acad Dermatol. 1994;31(6):978-81 (Epub 1994/12/01).

7. Asady A, Ruft J, Ellrich A, Hawro T, Maurer M, Altrichter S. Cholinergic urticaria patients of different age groups have distinct features. Clin Exp Allergy. 2017;47(12):1609-14 (Epub 2017/09/06).

8. Ruft J, Asady A, Staubach P, Casale T, Sussmann G, Zuberbier T, et al. Development and validation of the Cholinergic Urticaria Quality-of-Life Questionnaire (CholU-QoL). Clin Exp Allergy. 2018;48(4):433-44 (Epub 2018/01/26).

9. Poon E, Seed PT, Greaves MW, Kobza-Black A. The extent and nature of disability in different urticarial conditions. Br J Dermatol. 1999;140(4):66771 (Epub 1999/05/08).

10. Horikawa T, Fukunaga A, Nishigori C. New concepts of hive formation in cholinergic urticaria. Curr Allergy Asthma Rep. 2009;9(4):273-9 (Epub 2009/08/07).

11. Bito T, Sawada Y, Tokura Y. Pathogenesis of cholinergic urticaria in relation to sweating. Allergol Int. 2012;61(4):539-44 (Epub 2012/10/25).

12. Altrichter $\mathrm{S}$, Koch $\mathrm{K}$, Church MK, Maurer M. Atopic predisposition in cholinergic urticaria patients and its implications. J Eur Acad Dermatol Venereol. 2016;30(12):2060-5 (Epub 2016/06/22)

13. Adachi J, Aoki T, Yamatodani A. Demonstration of sweat allergy in cholinergic urticaria. J Dermatol Sci. 1994;7(2):142-9.

14. Metz M, Bergmann P, Zuberbier T, Maurer M. Successful treatment of cholinergic urticaria with anti-immunoglobulin E therapy. Allergy. 2008;63(2):247-9 (Epub 2008/01/12).

15. Metz M, Altrichter S, Ardelean E, Kessler B, Krause K, Magerl M, et al. Antiimmunoglobulin E treatment of patients with recalcitrant physical urticaria. Int Arch Allergy Immunol. 2011;154(2):177-80 (Epub 2010/08/25).

16. Hide M, Tanaka T, Yamamura Y, Koro O, Yamamoto S. IgE-mediated hypersensitivity against human sweat antigen in patients with atopic dermatitis. Acta Derm Venereol. 2002;82(5):335-40 (Epub 2002/11/15).

17. Hiragun M, Hiragun T, Ishii K, Suzuki H, Tanaka A, Yanase Y, et al. Elevated serum IgE against MGL_1304 in patients with atopic dermatitis and cholinergic urticaria. Allergol Int. 2014;63(1):83-93.

18. Hiragun T, Ishii K, Hiragun M, Suzuki H, Kan T, Mihara S, et al. Fungal protein MGL_1304 in sweat is an allergen for atopic dermatitis patients. J Allergy Clin Immunol. 2013;132(3):608-615.e4 (Epub 2013/06/04).

19. Tanaka A, Tanaka T, Suzuki H, Ishii K, Kameyoshi Y, Hide M. Semi-purification of the immunoglobulin E-sweat antigen acting on mast cells and basophils in atopic dermatitis. Exp Dermatol. 2006;15(4):283-90 (Epub 2006/03/04).

20. Takahagi S, Tanaka T, Ishii K, Suzuki H, Kameyoshi Y, Shindo H, et al. Sweat antigen induces histamine release from basophils of patients 
with cholinergic urticaria associated with atopic diathesis. Br J Dermatol. 2009;160(2):426-8 (Epub 2008/09/25).

21. Glatz M, Buchner M, von Bartenwerffer W, Schmid-Grendelmeier P, Worm $M$, Hedderich J, et al. Malassezia spp.-specific immunoglobulin E level is a marker for severity of atopic dermatitis in adults. Acta Derm Venereol. 2015;95(2):191-6 Epub 2014/04/04

22. Maurer M, Metz M, Bindslev-Jensen C, Bousquet J, Canonica GW, Church MK, et al. Definition, aims, and implementation of GA(2) LEN Urticaria Centers of Reference and Excellence. Allergy. 2016;71(8):1210-8.

23. Diepgen TL, Sauerbrei W, Fartasch M. Development and validation of diagnostic scores for atopic dermatitis incorporating criteria of data quality and practical usefulness. J Clin Epidemiol. 1996;49(9):1031-8.

24. Koch K, Weller K, Werner A, Maurer M, Altrichter S. Antihistamine updosing reduces disease activity in patients with difficult-to-treat cholinergic urticaria. J Allergy Clin Immunol. 2016;138(5):1483-1485.e9 (Epub 2016/08/09)

25. Altrichter S, Salow J, Ardelean E, Church MK, Werner A, Maurer M. Development of a standardized pulse-controlled ergometry test for diagnosing and investigating cholinergic urticaria. J Dermatol Sci. 2014;75(2):88-93 (Epub 2014/05/20).

26. Zuberbier T, Aberer W, Asero R, Abdul Latiff AH, Baker D, Ballmer-Weber B, et al. The EAACI/GA(2)LEN/EDF/WAO guideline for the definition, classification, diagnosis and management of urticaria. Allergy. 2018;73(7):1393414 (Epub 2018/01/18).

27. Fukunaga A, Bito T, Tsuru K, Oohashi A, Yu X, Ichihashi M, et al. Responsiveness to autologous sweat and serum in cholinergic urticaria classifies its clinical subtypes. J Allergy Clin Immunol. 2005;116(2):397-402 (Epub 2005/08/09)

28. Kan T, Hiragun T, Ishii K, Hiragun M, Yanase Y, Tanaka A, et al. Evaluation of recombinant MGL_1304 produced by Pichia pastoris for clinical application to sweat allergy. Allergol Int. 2015;64(3):266-71.

29. Savolainen J, Lintu P, Kosonen J, Kortekangas-Savolainen O, Viander $\mathrm{M}$, Pene J, et al. Pityrosporum and Candida specific and non-specific humoral, cellular and cytokine responses in atopic dermatitis patients. Clin Exp Allergy. 2001;31(1):125-34 (Epub 2001/02/13).

30. Nowicka D, Nawrot U. Contribution of Malassezia spp. to the development of atopic dermatitis. Mycoses. 2019;62(7):588-96 (Epub 2019/03/26)

31. Akaza N, Akamatsu H, Sasaki Y, Takeoka S, Kishi M, Mizutani H, et al. Cutaneous Malassezia microbiota of healthy subjects differ by sex, body part and season. J Dermatol. 2010;37(9):786-92 (Epub 2010/10/05).
32. Akaza N, Akamatsu H, Takeoka S, Sasaki Y, Mizutani H, Nakata S, et al. Malassezia globosa tends to grow actively in summer conditions more than other cutaneous Malassezia species. J Dermatol. 2012;39(7):613-6 (Epub 2012/01/11).

33. Ribbing C, Engblom C, Lappalainen J, Lindstedt K, Kovanen PT, Karlsson $M A$, et al. Mast cells generated from patients with atopic eczema have enhanced levels of granule mediators and an impaired Dectin-1 expression. Allergy. 2011;66(1):110-9 (Epub 2010/07/09).

34. Hirschmann JV, Lawlor F, English JS, Louback JB, Winkelmann RK, Greaves MW. Cholinergic urticaria. A clinical and histologic study. Arch Dermatol. 1987;123(4):462-7 (Epub 1987/04/01).

35. Hiragun $T$, Hiragun $M$, Ishii K, Kan T, Hide M. Sweat allergy: extrinsic or intrinsic? J Dermatol Sci. 2017;87(1):3-9 (Epub 2017/04/19).

36. Schmid-Grendelmeier P, Scheynius A, Crameri R. The role of sensitization to Malassezia sympodialis in atopic eczema. Chem Immunol Allergy. 2006;91:98-109 (Epub 2005/12/16).

37. Jinnestal CL, Belfrage E, Back O, Schmidtchen A, Sonesson A. Skin barrier impairment correlates with cutaneous Staphylococcus aureus colonization and sensitization to skin-associated microbial antigens in adult patients with atopic dermatitis. Int J Dermatol. 2014;53(1):27-33 (Epub 2013/07/25)

38. Broberg A, Faergemann J. Topical antimycotic treatment of atopic dermatitis in the head/neck area. A double-blind randomised study. Acta Derm Venereol. 1995;75(1):46-9 (Epub 1995/01/01).

39. Wong AW, Hon EK, Zee B. Is topical antimycotic treatment useful as adjuvant therapy for flexural atopic dermatitis: randomized, double-blind, controlled trial using one side of the elbow or knee as a control. Int J Dermatol. 2008;47(2):187-91 (Epub 2008/01/24).

40. Kozaru T, Fukunaga A, Taguchi K, Ogura K, Nagano T, Oka M, et al. Rapid desensitization with autologous sweat in cholinergic urticaria. Allergol Int. 2011;60(3):277-81 (Epub 2011/03/03).

41. Shindo H, Takahagi S, Mihara S, Tanaka T, Ishii K, Hide M, et al. Efficacy of sweat-antigen-inactivating skin care products on itching of patients with atopic dermatitis. Arerugi. 2011;60(1):33-42 (Epub 2011/02/25).

\section{Publisher's Note}

Springer Nature remains neutral with regard to jurisdictional claims in published maps and institutional affiliations.
Ready to submit your research? Choose BMC and benefit from:

- fast, convenient online submission

- thorough peer review by experienced researchers in your field

- rapid publication on acceptance

- support for research data, including large and complex data types

- gold Open Access which fosters wider collaboration and increased citations

- maximum visibility for your research: over $100 \mathrm{M}$ website views per year

At BMC, research is always in progress.

Learn more biomedcentral.com/submissions 